\title{
Evaluation of Measles Vaccine Virus as a Vector to Deliver Respiratory Syncytial Virus Fusion Protein or Epstein-Barr Virus Glycoprotein gp350
}

\author{
Hoyin Mok $^{\S}$, Xing Cheng ${ }^{\S}$, Qi Xu, James R. Zengel, Bandita Parhy, Jackie Zhao, C. Kathy Wang \\ and Hong Jin
}

MedImmune LLC., 319 North Bernardo Ave, Mountain View, California, USA

\begin{abstract}
Live attenuated recombinant measles vaccine virus (MV) Edmonston-Zagreb (EZ) strain was evaluated as a viral vector to express the ectodomains of fusion protein of respiratory syncytial virus (RSV F) or glycoprotein 350 of Epstein-Barr virus (EBV gp350) as candidate vaccines for prophylaxis of RSV and EBV. The glycoprotein gene was inserted at the $1^{\text {st }}$ or the $3^{\text {rd }}$ position of the measles virus genome and the recombinant viruses were generated. Insertion of the foreign gene at the $3^{\text {rd }}$ position had a minimal impact on viral replication in vitro. RSV F or EBV gp350 protein was secreted from infected cells. In cotton rats, EZ-RSV F and EZ-EBV gp350 induced MV- and insert-specific antibody responses. In addition, both vaccines also induced insert specific interferon gamma (IFN- $\gamma$ ) secreting T cell response. EZRSV F protected cotton rats from pulmonary replication of RSV A2 challenge infection. In rhesus macaques, although both EZ-RSV F and EZ-EBV gp350 induced MV specific neutralizing antibody responses, only RSV F specific antibody response was detected. Thus, the immunogenicity of the foreign antigens delivered by measles vaccine virus is dependent on the nature of the insert and the animal models used for vaccine evaluation.
\end{abstract}

Keywords: Measles vaccine, Edmonston-Zagreb, RSV F, EBV gp350, Cotton rats, Rhesus monkeys.

\section{INTRODUCTION}

Live attenuated viruses have been developed and used to help protect humans from various infectious diseases. Live attenuated vaccine viruses simulate natural infection and are highly immunogenic and effective in inducing both humoral and cellular immune responses. Because of their demonstrated safety and effectiveness against infectious diseases, different live attenuated vaccine viruses have been explored as vectors to express heterologous antigens [1]. Measles vaccine (MV) strain has a long history of demonstrated safety in humans. It induces long lasting immunity including antibody and $\mathrm{T}$ cell responses [2-4]. Aerosol administration of measles vaccine is also being developed and has been shown to induce similar or better immunogenicity compared to conventional subcutaneous or intramuscular vaccination $[5,6]$. This aerosol administration route may offer advantages in helping to protect individuals from mucosal pathogens.

The development of reverse genetics for negative stranded RNA viruses including measles virus has made it possible to explore the utility of the negative stranded RNA viruses to deliver foreign antigens. Measles vaccine virus has been explored by several laboratories to express foreign antigens such as the spike and nucleocapsid proteins of SARS coronavirus, HIV gp160, HPV L1 and hepatitis B surface antigens [7-10]. The vectored MV induces robust antibody and $\mathrm{T}$ cell responses against both insert antigens

*Address correspondence to this author at the MedImmune, 319 North Bernardo Ave, Mountain View, CA 94043, USA; Tel: 650603 2367; Fax: 650603 3367; E-mail: jinh@medimmune.com

${ }^{\S}$ Both authors contributed to the work equally. and MV [7-18], making it an attractive option for vaccination against measles as well as other infectious agents. Although some studies showed that MV could boost measles virus immune response in school aged children who had previously received measles vaccine $[19,20]$, the preexisting immunity to measles virus may reduce the immunogenicity of the vectored measles vaccine $[21,22]$. Thus, the utility of MV vector in measles seropositive population remains to be determined. Several studies performed in the early 1980 s in developing countries revealed that high seroconversion rates were achieved with EZ measles vaccine despite the presence of high titer of maternal measles virus antibody [23]. Therefore, the EZ strain might be immunogenic in populations with histories of measles vaccination or preexisting MV immunity.

In this study, we explored the use of the EZ vaccine strain to deliver viral antigens for prevention of RSV and EBV associated diseases. RSV causes severe lower respiratory tract illness in infants and the elderly. Bronchiolitis from RSV infection in infants is associated with recurrent wheezing and asthma in childhood [24]. No vaccine is available to prevent morbidity and mortality from RSV infection. The surface fusion (F) protein of RSV is a major antigenic protein that induces neutralizing antibodies, $\mathrm{CD}^{+}$cytotoxic $\mathrm{T}$ lymphocytes, and protection against subsequent RSV challenge in mice or cotton rats [25]. High levels of $\mathrm{F}$ neutralizing antibodies are sufficient to protect the lower respiratory tract infection [26] and have been used for prophylactic purpose in infants.

EBV is a gamma herpes virus that causes infectious mononucleosis in adolescents [27]. In addition, EBV has been associated with certain malignancies including Burkitt's lymphoma, post-transplantation lymphoprolifera- 
tive disease, lymphoma and nasopharyngeal carcinoma [28]. There is no prophylactic EBV vaccine available. The surface glycoprotein gp350, which binds to human $\mathrm{CD} 21$ receptor on B cells to mediate viral entry, has been identified as a protective antigen. The adjuvanted EBV gp350 protein has been shown to be efficacious in a randomized phase II study in preventing infectious mononucleosis [29]. Here, we report the construction of an infectious measles virus by reverse genetics system and the insertion of the $\mathrm{F}$ protein of respiratory syncytial virus or gp350 of EBV into MV virus as a separate transcriptional unit. The vectored viruses were then evaluated in cotton rats and rhesus macaques for their immunogenicity.

\section{MATERIALS AND METHODS}

Viruses and cells. RSV A2 strain was obtained from ATCC (Manassas, MA). EZ vaccine strain was from Serum Institute of India (Pune, India). Vero and HEp-2 cells were maintained in Dulbecco's modified Eagles's medium (Invitrogen, Carlsbad, CA) supplemented with $2 \%$ fetal bovine serum (FBS), $2 \mathrm{mM}$ L-glutamine, and $1 \%$ penicillin/streptomycin at $37^{\circ} \mathrm{C}$ with $5 \% \mathrm{CO}_{2}$.

Construction of Measles vaccine virus rescue system. Antigenomic cDNA was synthesized by DNA2.0 (Menlo Park, CA) based on the sequence of live attenuated measles virus Edmonston-Zagreb strain (NCBI DNA accession number F266290). The T7 RNA polymerase promoter sequence was added to the 5 ' end of the antigenomic cDNA and the hepatitis delta virus ribozyme and a T7 RNA polymerase terminator sequences were added to the 3' end of the antigenomic cDNA. Sequence at nucleotides 5502 (Sca I) and 9343 (Mlu I) was modified to facilitate cDNA cloning. The three amino acid residues at positions 3682, 3862 and $10555\left(3682_{\mathrm{K} \rightarrow \mathrm{R}}, 3862_{\mathrm{S} \rightarrow \mathrm{N}}, 10555_{\mathrm{K} \rightarrow \mathrm{R}}\right)$ that were different from the EZ vaccine strains were corrected by sitedirected mutagenesis. The MV antigenomic cDNA was cloned into pUC18 vector and denoted as pEZ (Fig. 1). Supporting plasmids encoding measles $\mathrm{N}, \mathrm{P}$ and $\mathrm{L}$ genes were cloned into pCITE plasmids under the control of T7 promoter as previously described and were designed $\mathrm{pN}, \mathrm{pP}$ and $\mathrm{pL}$ respectively [30].

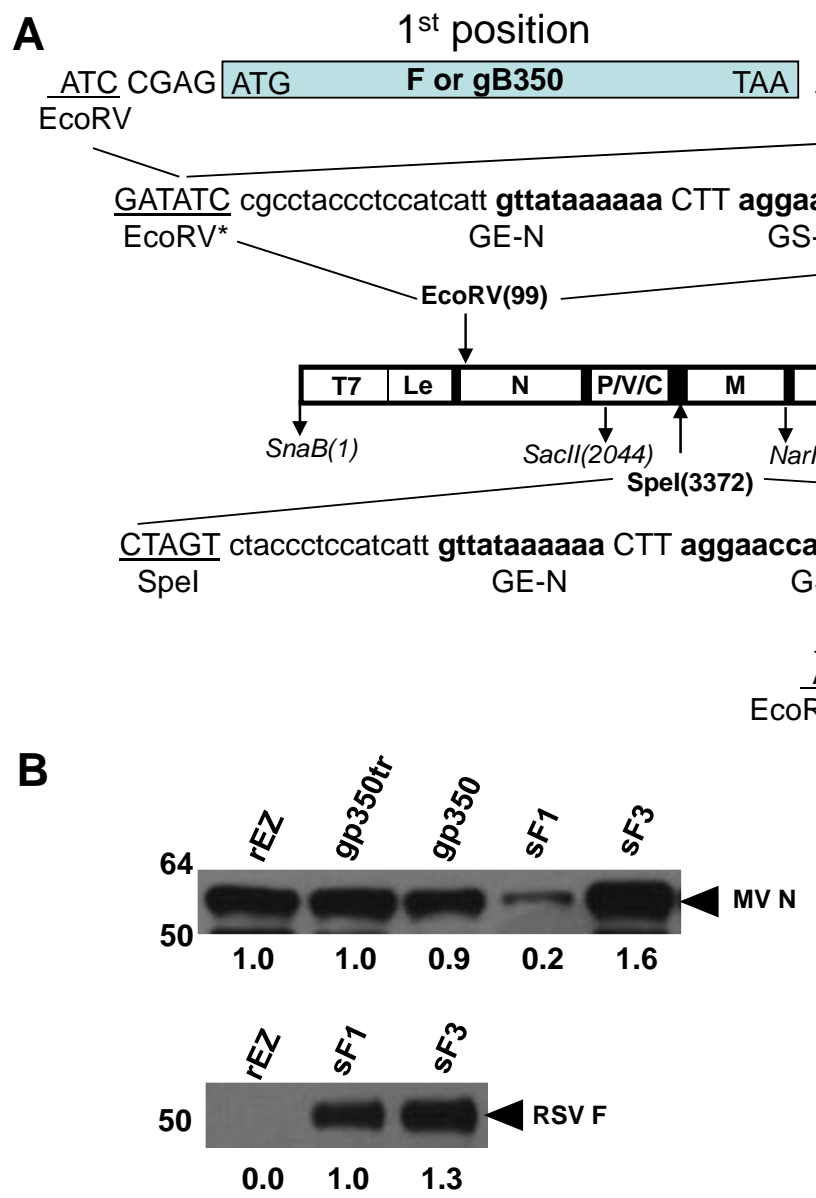

AGC Afel

GATATC cgcctaccctccatcatt gttataaaaaa CTT aggaaccaggtccacac agccgccagcccatca AAT

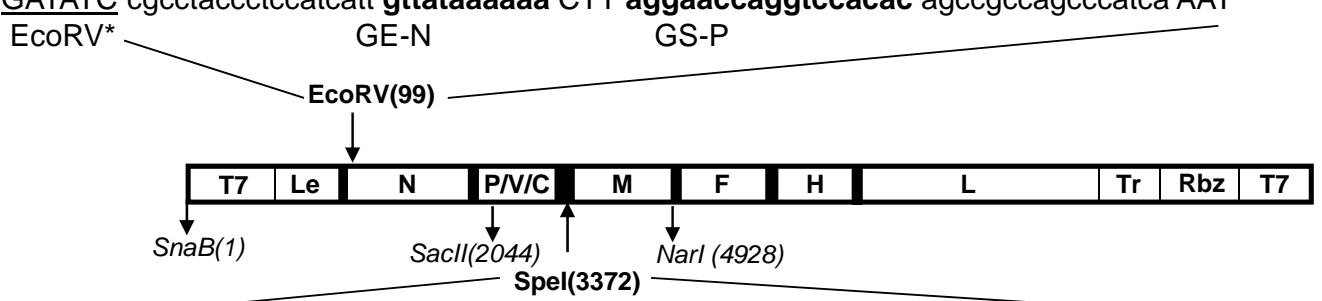

$\frac{\widehat{C T A G T} \text { ctaccctccatcatt gttataaaaaa CTT aggaaccaggtccacac agccgccagccatca GATATCA at AGCGCT T }}{\text { Spel }}$

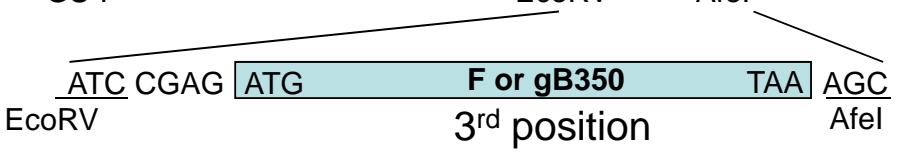

Fig. (1). Construction of measles vaccine vectors encoding ecto domains of RSV F and EBV gp350 and protein expression in virus-infected Vero cells. (A) RSV F ectodomain and EBV gp350 ectodomains were inserted in the $1^{\text {st }}$ and $3^{\text {rd }}$ transcription units of the measles Zagreb strain genome. Insertion was performed in the non-coding region 3' proximally of the MV N gene or between $\mathrm{P}$ and $\mathrm{M}$ genes of pEZ under the control of additional measles transcriptional units containing gene stop (GE)-gene start (GS) sequences. *RSV F gene (aa. 1-524) was inserted into EcoRV site using blunt ligation. " EBV gp350 full length (aa. 1-960), EBV gp350 truncated (aa. 1-470) or RSV F gene was inserted between EcoRV and AfeI site. (B) Vero cells were infected at an MOI of 3.0 with measles viruses encoding soluble RSV F (sF1 or $\mathrm{sF} 3$ ) or soluble EBV gp350 (gp350 or gp350 tr). After $18 \mathrm{~h}$, western blots were used to detect presence of measles virus nucleoprotein in infected Vero cell lysates or RSV F protein, EBV gp350 protein in the supernatant. Black arrowheads indicate the predicted molecular masses of the proteins. Relative intensity of the MV N protein bands was expressed as the intensity of the band relative to the rEZ control. 
Construction of measles virus vectored antigenomic cDNA. The ectodomain of RSV F and EBV gp350 ectodomains were inserted into the non-coding region $3^{\prime}$ proximal of the $\mathrm{N}$ gene or in the junction between the $\mathrm{P}$ and $\mathrm{M}$ genes of pEZ (Fig. 1). Each inserted gene contained measles virus transcriptional unit consisting of the sequences of $\mathrm{N}$ gene stop (GE-N) and P gene start (GS-P). To insert the RSV F gene into the promoter proximal location, a pUCSnaBI/SacII (pUC-S/S) subclone that contained the T7 promoter and MV sequence of 1 to 2044 with a silent mutation at nt 821 to knockout EcoRV enzyme site was generated. A gene cassette containing the ectodomain of RSV-F (aa 1-524) followed by GE-N and GS-P sequence were inserted into EcoRV site at nt 99. The genomic DNA was in multiples of 6 nucleotides (the rule of six). The SnaB I-Sac II fragment was swiped back to $\mathrm{pEZ}$ antigenomic cDNA (Fig. 1A) and the resulting cDNA was denoted as pEZ-RSVsF1.

To insert the RSV F gene and EBV gp350 gene into pEZ between the $\mathrm{P}$ and $\mathrm{M}$ genes, a pUC-SacII/NarI (pUC-S/N) subclone that contained the MV sequence of $2045 \mathrm{nt}$ to 4924 nt was constructed. A gene cassette containing gene end (GE) of N, gene start (GS) of P and ectodomain of RSV-F (aa 1-524), full length (aa $1-861$ ) or truncated (aa 1-470) ectodomain of gp350 at SpeI site (nt 3372). The Sac II to Nar I fragment was swiped back to $\mathrm{pEZ}$ antigenomic cDNA (Fig. 1A) and the resulting cDNA was denoted as pEZRSVsF3, pEZ-EBVgp350 and pEZ-EBVgp350tr respectively.

Generation of recombinant measles virus and vectored measles viruses. Rescue of the recombinant viruses from MV antigenomic cDNA was performed as previously described $[16,30,31]$. Briefly, HEp-2 cells were infected with MVA-T7 at a multiplicity of infectivity (moi) of 5 for an hour prior to transfection. A DNA mixture of $\mathrm{pEZ}$ $(0.8 \mu \mathrm{g}), \mathrm{pN}(0.4 \mu \mathrm{g}), \mathrm{pP}(0.4 \mu \mathrm{g})$ and $\mathrm{pL}(0.2 \mu \mathrm{g})$ were cotransfected into MVA-T7 infected HEp-2 cells using Lipofectamine 2000 (Invitrogen, Carlsbad, CA). The culture medium was replaced with DMEM containing $2 \%$ FBS after overnight incubation at $37^{\circ} \mathrm{C}$. The transfected cells were incubated for an additional 3 to 4 days and the culture supernatant was used to infect fresh Vero cells to amplify the rescued virus. The rescued viruses were then plaque purified twice in Vero cells. The viruses rescued from pEZ, pEZRSVsF1, pEZ-RSVsF3, pEZ-EBVgp350 and pEZEBVgp350tr were designated as $\mathrm{rEZ}, \mathrm{sF} 1, \mathrm{sF} 3, \mathrm{gp} 350$ and gp350tr, respectively.

Evaluation of recombinant measles viruses for their replication in cell cultures. Replication kinetics of rEZ, gp350, gp350tr, $\mathrm{sF} 1$ or $\mathrm{sF} 3$ viruses was compared in Vero cells. Vero cells in six-well plates were infected with each virus at a MOI of 0.01 in triplicates. After a 1 hour adsorption at room temperature, the cells were washed three times with phosphatebuffered saline (PBS) and incubated with $2 \mathrm{~mL}$ of complete DMEM at $35^{\circ} \mathrm{C}$ with $5 \% \mathrm{CO}_{2}$. Aliquots of culture supernatant were collected daily from each well for 7 days and stored at $80^{\circ} \mathrm{C}$ until virus titration. Viral titers were determined by plaque assay in Vero cells as previously described [32]. Replication kinetic was performed twice in triplicate and each supernatant sample was titered in duplicate.
Western blot. Vero cells were infected at a MOI of 3.0 with rEZ, gp350, gp350tr, sF1 or sF3 for 18 hours at $37^{\circ} \mathrm{C}$. Culture supernatant and cells were harvested separately. The cells were scraped and pelleted for $10 \mathrm{sec}$ at $6,000 \mathrm{rpm}$ in microfuge tubes and lysed in lysis buffer $(50 \mathrm{mM}$ Tris- $\mathrm{HCl}$, $150 \mathrm{mM} \mathrm{NaCl}, 1 \%$ Triton X-100, $0.5 \%$ [vol/vol] protease inhibitor cocktail, $\mathrm{pH}$ 8.0) (Sigma, St. Louis, MO) for 10 min on ice. The resulting cell lysates were cleared by centrifugation at 13,000 rpm for $5 \mathrm{~min}$.

Proteins from culture supernatant or cell lysates were separated by electrophoresis and transferred onto a PVDF membrane. Viral proteins were detected with anti-measles nucleoprotein (clone 2D7, Santa Cruz Biotechnology), polyclonal rabbit EBV gp350 [33] or monoclonal antibody against RSV F proteins (palivizumab, MedImmune, Gaithersburg, MD) antibodies. Intensities of the bands were quantified by ImageQuant software (GE Healthcare, Piscataway, NJ). Relative intensity was determined by comparing pixel intensity of the band relative to the rEZ control.

Cotton rat studies. Specific-pathogen-free 6- to 8-weekold cotton rats were purchased from Harlan (Indianapolis, IN). The animal study protocol was approved by MedImmune's Institutional Animal Care and Use Committee. Animals were anesthetized with isoflurane by inhalation and vaccinated intramuscularly (i.m.) with $10^{5}$ PFU of rEZ, gp350tr, gp350, sF1 or sF3 in a $200 \mu 1$ inoculum volume. The control groups were inoculated intramuscularly (i.m) with PBS, $10^{5}$ PFU of UV-inactivated $\mathrm{sF} 3$, or intransally (i.n) with $10^{6} \mathrm{PFU}$ of RSV A2 strain. The animals were boosted with the same dose of viruses 4 weeks later.

The animals were observed for clinical signs daily and bled at 14-day intervals to measure antibody responses. Twenty-eight days after the second immunization, the cotton rats from measles virus vectored RSV vaccine groups were challenged with $10^{6} \mathrm{PFU}$ of RSV A2 strain i.n. The lungs were harvested on day 4 post-challenge and viral titers were determined by plaque assay.

Rhesus macaque study. Adult rhesus macaques aged 39 year-old were used for the immunogenicity study at Valley Biosystems (West Sacramento, CA). All experimental procedures were approved by the Institutional Animal Use and Care Committee at MedImmune and Valley Biosystems. Measles vaccine immunization history of the rhesus macaques was confirmed by neutralization assay prior to the study. A total of 16 rhesus macaques ( 8 measles virus seropositive, 8 naïve) were used in the study. Half of the animals (4 measles virus sero-positive, 4 naïve) received two doses of gp350 intramuscularly using $10^{5} \mathrm{PFU} /$ inoculation and the other half received two doses of $\mathrm{sF} 3$ at the same dose intramuscularly. The inoculations were performed at 4 week intervals. Blood was drawn from each animal every 14 days to assess immune responses. Animals were anesthetized with ketamine intramuscularly at each procedure. Clinical symptoms were monitored by veterinarians for the duration of the study.

EBV gp350 and RSV F protein-specific ELISA assay. EBV gp350- or RSV F-specific enzyme-linked immunosorbent assay (ELISA) were performed to determine the levels 
of gp350 or F protein-specific antibodies. Briefly, $100 \mathrm{ng}$ of purified recombinant soluble EBV gp350 or RSV F protein expressed from mammalian cells was adsorbed onto Immulon $2 \mathrm{~B}$ plates overnight in PBS at $4{ }^{\circ} \mathrm{C}$. The plate was blocked with 5\% BSA in PBS. Serial dilutions of animal sera in $\mathrm{PBS} / 1 \% \mathrm{BSA}$ were added to the plate and incubated for an hour at room temperature. After washing, HRP-conjugated anti-cotton rat IgG (Immunology Consultants Laboratory, Newberg, OR) or anti-rhesus macaques IgG (Rockland Immunochemicals, Boyertown, PA) were added and incubated for 1 hour. Finally, the plate was developed with tetramethylbenzidine peroxidase substrate (KPL, Rockford, IL) and stopped with $\mathrm{HCl}$. Absorbances of the samples were read at $450 \mathrm{~nm}$ and the titer for each sample was calculated by determining the dilution at which the absorbance reached 2 times over the reading of no serum control. The lower limits of detection were $3.3 \log _{2}$ and $6.6 \log _{2}$ for EBV gp350 ELISA and RSV F ELISA, respectively.

Neutralization assays. Measles virus specific neutralizing antibodies were determined as described previously [34] in 96-well plates using Vero cells. Neutralizing antibody titer is defined as the highest dilution that inhibits 50\% CPE. RSV specific neutralizing antibody was determined by the plaque reduction neutralization assay as described previously [35]. The lower limit of detection was $4.3 \log _{2}$ and $3.0 \log _{2}$ for MV microneutralization and RSV plaque reduction assays, respectively. EBV specific neutralizing antibody titer was determined by the method described by Sashihara et al.,[36].

ELISPOT assay. ELISpot assays were performed with spleens from vaccinated and control cotton rats 14 days after the second dose and peripheral blood mononucleocyte cells (PBMC) of rhesus monkeys 28 days after the second dose. Splenocytes were isolated as previously described [37]. Splenocytes were counted using Vi-Cell (Beckman Coulter, Brea, CA). Gamma interferon (IFN- $\gamma$ ) and Interleukin 4secreting $\mathrm{T}$ cells were quantified in an enzyme-linked immunospot (ELISpot) assay using R\&D DuoSet ELISA System for cotton rat IFN- $\gamma$ and IL-4 antibodies (R\&D Systems, Minneapolis, MN) as previously described using $10 \mu \mathrm{g} / \mathrm{mL}$ of EBV gp350 or RSV F proteins for stimulation [38]. Spots were scanned and counted by ImmunoSpot spot Analyzer (Cellular Technology, Cleveland, OH). The numbers of IFN- $\gamma$ or IL-4 secreting cells were expressed as the number cells per $10^{6}$ cells.

Statistics. GraphPad Prism software was used to analyze the data (GraphPad Software Inc., San Diego, CA). All data were expressed as the mean and standard error. The data were also analyzed by Mann-Whitney rank sum test to compare data distribution between any two experimental groups. Titer comparison between viruses in replication kinetic experiment was performed using the Kruskal-Wallis test, assuming non-parametric distribution.

\section{RESULTS}

\section{Cloning and Expression of RSV and EBV Antigens from Measles Virus}

The reverse genetics system for measles EdmonstonZagreb (EZ) vaccine virus was established by transfecting
$\mathrm{MV}$ antigenomic plasmid $\mathrm{pEZ}$ together with $\mathrm{pP}, \mathrm{pN}$ and $\mathrm{pL}$ into MVA-T7 infected HEp-2 cells to recover infectious EZ virus. To generate rEZ expressing RSV F or EBV gp350, the F ectodomain of RSV and EBV gp350 were cloned into the MV antigenomic cDNA (Fig. 1A). The F was cloned at the two positions of the viral genome: one proximal to the $\mathrm{N}$ gene $\left(1^{\text {st }}\right.$ position) and the other between the $\mathrm{P}$ and $\mathrm{M}$ genes ( $3^{\text {rd }}$ position). EBV gp350 ectodomain and its $\mathrm{N}$-terminal half of the gp350 (amino acid 1-470, gp350tr) that encoded the receptor binding site to CD21 [39] were also cloned into the EZ genome at the $1^{\text {st }}$ and $3^{\text {rd }}$ positions. Recombinant EZ with RSV F, EBV gp350 and EBV gp350tr inserted at the $1^{\text {st }}$ or $3^{\text {rd }}$ position were generated. However, viruses with gp350 and gp350tr inserted at the $1^{\text {st }}$ position replicated poorly in vitro and were not evaluated further. The rescued recombinant viruses expressing $\mathrm{RSV} F$ or EBV gp350 or gp350tr were designed as $\mathrm{sF} 1$ ( $\mathrm{F}$ at the $1^{\text {st }}$ position), $\mathrm{sF} 3$ ( $\mathrm{F}$ at the $3^{\text {rd }}$ position), gp350 and gp350tr (both at the $3^{\text {rd }}$ position), respectively.

To confirm that these recombinant measles viruses expressed the desired antigens, the expression of the inserts in infected Vero cells was examined by Western blotting analysis. In addition to MV N protein that was detected in infected cell lysate (Fig. 1B), RSV F and EBV gp350 were detected in the culture supernatant of the infected cells (Fig. 1B), indicating the production of secreted form of RSV F and EBVgp350 proteins from virus infected cells. The observation of lower MV N expression in Vero cells infected with $\mathrm{sF} 1$ compared to other viruses may be attributed to the insertion of RSV $\mathrm{F}$ proximal to the MV $\mathrm{N}$ gene, which moved the MV N gene to the $2^{\text {nd }}$ position of the genome and reduced its mRNA transcript level. The relative expression of RSV F to MV N, however, was shown to be higher for $\mathrm{sF} 1$ compared to $\mathrm{sF} 3$. This is consistent with the observation that genes proximal to 3' end of the genome are transcribed more abundantly than those downstream and more RSV F was produced from $\mathrm{sF} 1$ than $\mathrm{sF} 3$ per virion.

Viral replication efficiency of these recombinant viruses was assessed by growth kinetics in Vero cells. Both recombinant EZ (rEZ) and EZ vaccine viruses grew to a peak titer of $7.9 \log _{10} \mathrm{PFU} / \mathrm{mL}$ on day 5 (Fig. 3A). rEZ with either RSVF (Fig. 2A) or EBVgp350 (Fig. 2B) inserts had comparable growth kinetics but slightly lower (between 0.1 $0.7 \log _{10}$ lower) than rEZ. The peak titers between the viruses were not statistically different. sF3 had a faster growth kinetics and reached peak titer on day 3 instead of day 5. Therefore, insertion of RSV F or EBV gp350 into the genome of EZ did not significantly reduce viral growth in vitro.

\section{Evaluation of Antibody Response in Cotton Rats}

Cotton rats had previously been demonstrated to be semipermissive to measles virus infection [40] and are the best available small animal model for MV infection. In addition, cotton rats are susceptible to RSV infection and have been used in the evaluation of RSV vaccines [41, 42] and antiRSV antibody investigated for prophylactic application [43]. The ability of rEZ vectored vaccines to induce humoral responses to measles virus and RSV F or EBV gp350 protein were assessed in cotton rats. Cotton rats were immunized 
A

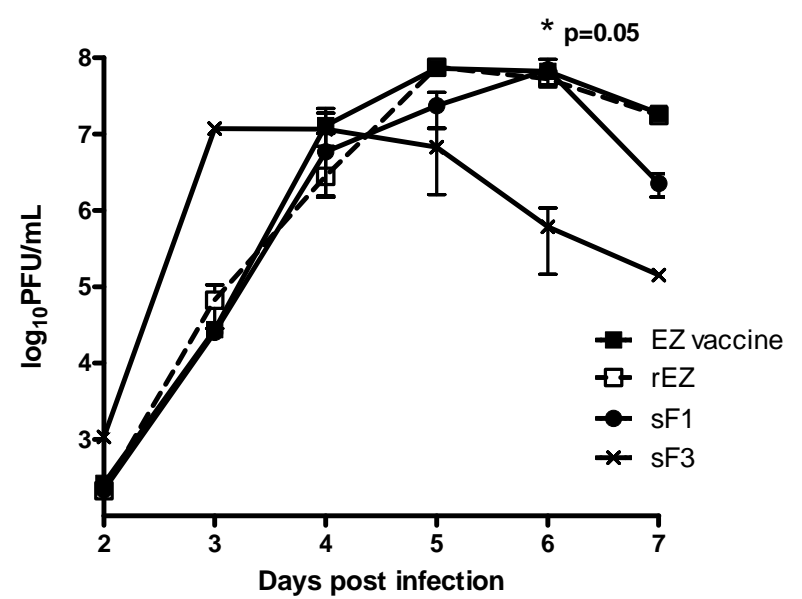

B

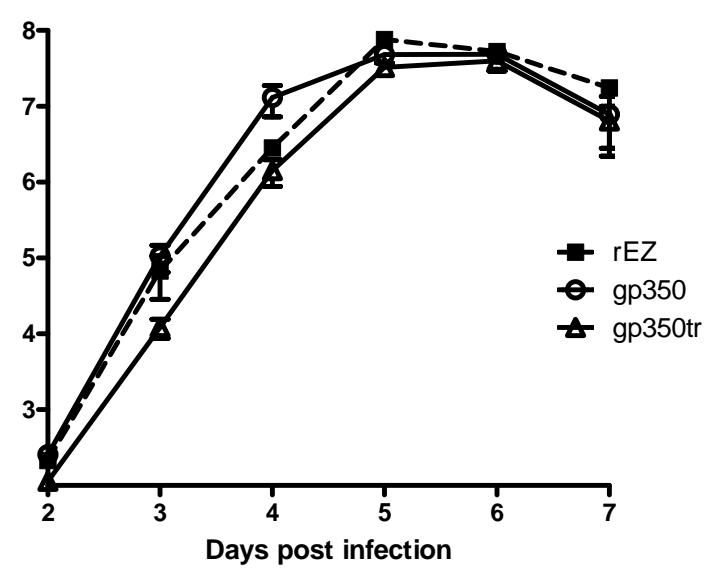

Fig. (2). Growth kinetics of measles vectors encoding soluble RSV F or soluble EBV gp350 was similar to that of recombinant measles constructs. Vero cells were infected at MOI of 0.01 with measles vectors. Cells were incubated at $35^{\circ} \mathrm{C}$ for 7 days. Cells and supernatant were sampled daily for virus titers using standard plaque assay. ${ }^{*}$ denotes statistically significant difference in titer of sF3 versus $\mathrm{sF} 1, \mathrm{rEZ}$ and EZ using the Kruskal-Wallis test.
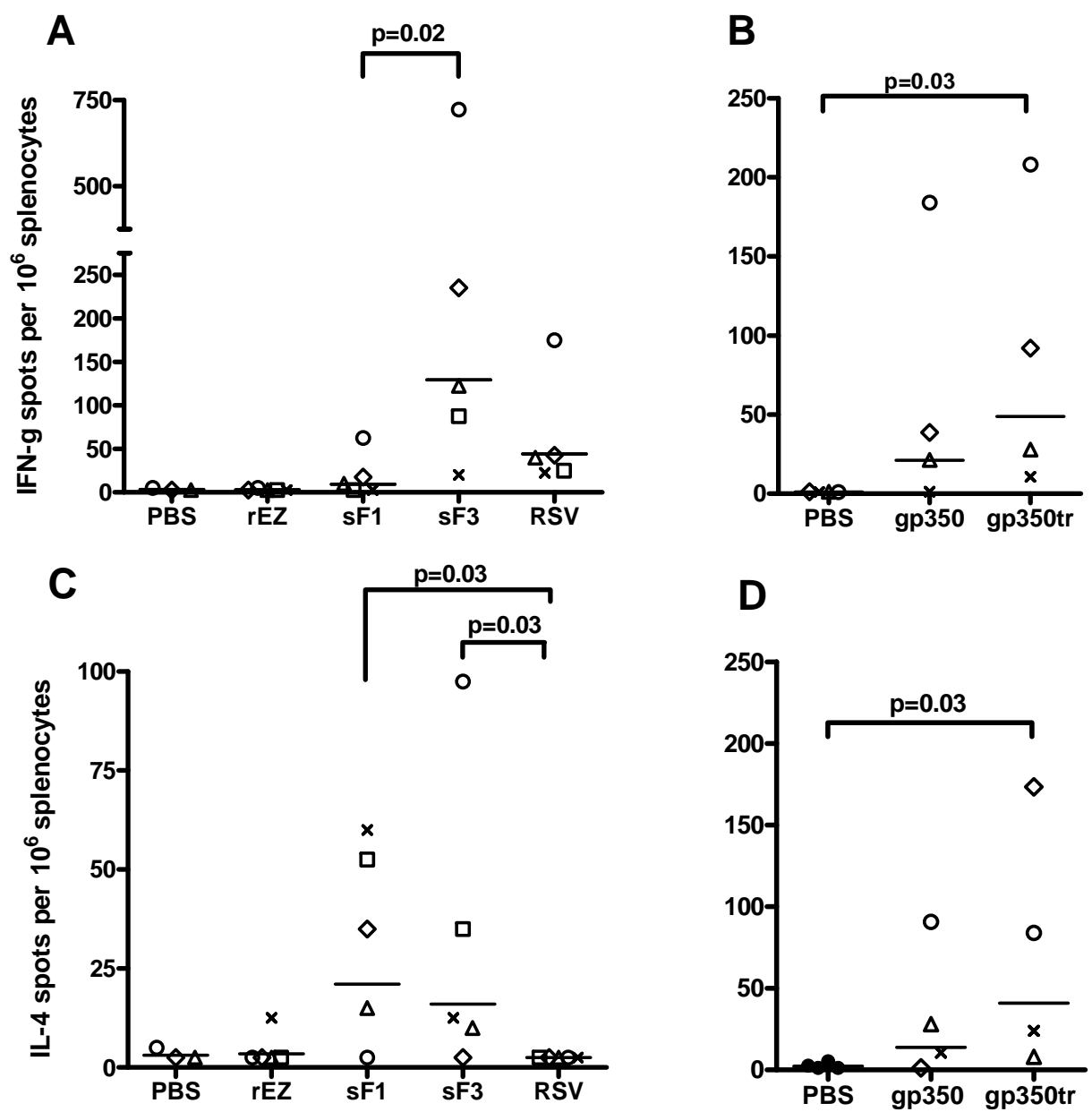

Fig. (3). RSV F-specific and EBV gp350-specific splenocytes were induced in the spleens of cotton rats immunized i.m. with measles vectors. Cotton rats were vaccinated on days 0 and 28 with measles vectors. Splenocytes were harvested 7 days after the second measles vectors vaccination. A total of $3 \times 10^{5}$ cells were stimulated with either RSV F protein (A and C) or EBV gp350 protein (B and D) in vitro for $20 \mathrm{~h}$, and the numbers of IFN- $\gamma$ spot-forming cells (A and B) and IL-4 spot-forming cells (C and D) were quantified by an ELISPOT assay. Spots were counted with an automated counting device and are expressed as numbers of spots per $10^{6}$ cells. Groups are compared using Mann-Whitney rank sum test. Each symbol represents an individual animal. 
Table 1. Antibody response of cotton rats to rEZ vectored gp350 and RSV F

\begin{tabular}{|c|c|c|c|c|c|c|}
\hline \multirow[b]{2}{*}{ Inoculation } & \multicolumn{2}{|c|}{ MV Neutralizing Ab (Mean $\log _{2} \pm$ SD Titer $)^{\mathrm{b}, \mathrm{e}}$} & \multicolumn{2}{|c|}{$\begin{array}{l}\text { EBV-gp350 or RSV-F ELISA Ab } \\
\quad{\left.\text { (Mean } \log _{2} \pm \text { SD Titers) }\right)^{\mathrm{c}, \mathrm{e}}}^{\text {So }}\end{array}$} & \multicolumn{2}{|c|}{$\begin{array}{l}\text { RSV or EBV Neutralizing Ab } \\
\quad\left(\text { Mean } \log _{2} \pm \text { SD Titer) }\right)^{\mathrm{d}, \mathrm{e}}\end{array}$} \\
\hline & Dose $1^{a}$ & Dose $2^{\mathrm{a}}$ & Dose 1 & Dose 2 & $\overline{\text { Dose } 1}$ & $\begin{array}{l}\text { Dose } 2 \\
\end{array}$ \\
\hline $\mathrm{rEZ}$ & $8.4 \pm 0.4$ & $10.1 \pm 0.9$ & $<3.3$ & $<3.3$ & $<3.3$ & $<3.3$ \\
\hline gp350 & $8.7 \pm 0.6$ & $11.0 \pm 0.7$ & $3.3 \pm 0.1$ & $7.3 \pm 0.3$ & $<3.3$ & $<3.3$ \\
\hline gp350tr & $8.2 \pm 0.2$ & $10.2 \pm 0.8$ & $3.3 \pm 0.1$ & $4.3 \pm 0.1$ & $<3.3$ & $<3.3$ \\
\hline rEZ & $7.1 \pm 0.4$ & $8.7 \pm 0.6$ & $<6.6$ & $<6.6$ & $<3.0$ & $<3.0$ \\
\hline $\mathrm{sF} 1$ & $6.7 \pm 0.5$ & $8.7 \pm 0.9$ & $15.9 \pm 2.7$ & $23.7 \pm 1.2$ & $5.4 \pm 0.7$ & $7.5 \pm 1.0$ \\
\hline $\mathrm{sF} 3$ & $6.3 \pm 0.0$ & $8.7 \pm 1.1$ & $15.5 \pm 0.9$ & $22.1 \pm 0.8$ & $4.2 \pm 1.0$ & $8.9 \pm 1.1$ \\
\hline
\end{tabular}

${ }^{\mathrm{a}}$ Serum samples were measured 4 weeks post dose 1 and 2 weeks post dose 2 .

${ }^{\mathrm{b}}$ Titer is defined as $\log 2$ reciprocal dilution of serum that inhibited cytopathic effects in $50 \%$ of the wells containing measles infected Vero cells

${ }^{c}$ Titer is defined as $\log 2$ of the highest dilution of serum that gave $\mathrm{OD}_{450}$ reading $2 \mathrm{x}$ of the background.

${ }^{\mathrm{d}} \mathrm{RSV}$ titer is defined as $\log 2$ reciprocal dilution of serum that reduced plaques on HEp- 2 cells by $50 \%$.

${ }^{\mathrm{e}}$ Titer on day 0 for all assays were under the limit of detection.

with two doses of rEZ viruses intramuscularly at 4 weeks interval. Sera were collected 4 weeks post dose 1 and 2 weeks post dose 2. Measles virus neutralizing antibodies (MV $\mathrm{Ab})$ were induced rapidly after one dose administration, reaching titers of 6.3-8.7 $\log _{2}$. No significant differences in MV Ab titers were observed among the animals receiving $\mathrm{sF} 1, \mathrm{sF} 3$, gp350 or gp350tr compared to rEZ. The $2^{\text {nd }}$ dose increased MV Ab titers by 2-4 folds (Table 1). The control animals vaccinated with UVinactivated $\mathrm{sF} 3$ or RSV A2 virus did not have detectable MV $\mathrm{Ab}$ titer (data not shown).

RSV-specific antibody responses were measured by RSV F-specific ELISA and microneutralization assay. $\mathrm{sF} 1$ or $\mathrm{sF} 3$ induced RSV F-specific IgG antibody in the vaccinated cotton rats (about 15.5-15.9 $\log _{2}$ post dose 1 and 22.1-23.7 $\log _{2}$ post dose 2). The RSV F-specific IgG antibody titers were similar between the $\mathrm{sF} 1$ and $\mathrm{sF} 3$ vaccinated groups. RSV neutralizing antibody titers were also measured against RSV A2 strain. After the first dose, $\mathrm{sF} 1$ and $\mathrm{sF} 3$ induced RSV neutralizing $\mathrm{Ab}$ and titers were boosted to $7.5-\log _{2}$ and $8.9-\log _{2}$ after the second dose (Table 1). There was no statistical difference in antibody response between $\mathrm{sF} 1$ and $\mathrm{sF} 3$ vaccinated animals and those intranasally infected with 2 doses of RSV A2 strain (9.4 $\log _{2} \pm 1.5$, data not shown). Animals vaccinated with $\mathrm{UV}$-inactivated $\mathrm{sF} 3$ did not have detectable RSV antibody (data not shown), indicating that virus immunogenicity was dependent on live virus infection.

EBV-specific antibody response was measured by EBV gp350-specific ELISA assay. EBV specific ELISA Ab response was detected after one dose administrations of gp350 or gp350tr; after the $2^{\text {nd }}$ dose the titers reached 7.3 and $4.3 \log _{2}$ for gp350 and gp350tr vaccinated animals, respectively (Table 1). Gp350 induced a significantly higher EBV gp350-specific IgG titer than gp350tr. EBV specific neutralizing antibody could not be detected by the EBV neutralization assay.

\section{Evaluation of Cell Mediated Immune Response in Vaccinated Cotton Rats}

Cell mediated immune response is important for viral clearance and may play an important role in vaccine mediated protective immune response [44]. RSV F-specific and EBV gp350-specific $\mathrm{T}$ cell responses in splenocytes were examined by IFN- $\gamma$ and IL-4 ELISpot on day 7 post the $2^{\text {nd }}$ dose. The frequencies of RSV F-specific IFN- $\gamma$ secreting cells were statistically higher in $\mathrm{sF} 3$ vaccinated group (average 130 spots $/ 10^{6}$ splenocytes) compared to $\mathrm{sF} 1$ vaccinated (average 9 spots $/ 10^{6}$ splenocytes) or RSV A2infected animals (average 45 spots $/ 10^{6}$ splenocytes) (Fig. 3A). The RSV F-specific IL-4 secreting cells were low, averaged about 20 spots $/ 10^{6}$ splenocytes for both $\mathrm{sF} 1$ and sF3 groups. Surprisingly, no RSV-specific IL-4 secreting cells detected in RSV A2-infected animals (Fig. 3C). Thus, sF3 and RSV induced a Th1-biased response based on the higher IFN- $\gamma$ to IL-4 secreting cell ratio.

The frequencies of EBV gp350-specific IFN- $\gamma$ and IL-4 secreting cells for gp 350 (average 23 spots and 15 spots $/ 10^{6}$ splenocytes for IFN- $\gamma$ and IL-4 respectively) and gp350tr vaccinated groups (average 49 spots and 41 spots $/ 10^{6}$ splenocytes for IFN- $\gamma$ and IL-4 respectively) were not statistically different, but were statistically higher than the PBS control group for the gp350tr group (Fig. 3B, D).

\section{Protection Against RSV A2 Challenge in sF1 and sF3 Vaccinated Cotton Rats}

Animal model is not available for assessing EBV vaccine induced protective immune response. Cotton rat is the best available small animal model to evaluate RSV vaccine induced protection against wt RSV challenge infection. To assess if the immune responses induced from $\mathrm{sF} 1$ and $\mathrm{sF} 3$ could provide protection against RSV A2 challenge, vaccinated cotton rats were challenged with RSV A2 intranasally and virus titers in the lungs were measured. Similar to RSV infected animals, $\mathrm{sF} 1$ or $\mathrm{sF} 3$ offered complete protection against RSV A2 challenge with viral titers in the lungs that was at least $4.5 \log _{10}$ lower than the control animals. In contrast, cotton rats vaccinated with $10^{5}$ PFU of UV-inactivated $\mathrm{sF} 3$ had viral titer similar to the PBS control group, indicating that viral replication is necessary for induction of protective immune response (Fig. 4).

\section{Immunogenicity of EZ Vectored Vaccines in Rhesus Macaques}

Rhesus macaques are fully permissive to measles virus infection and have been used for evaluation of measles 
vaccine and measles virus pathogenesis studies [45-47]. The ability of rEZ vectored RSV F and EBV gp350 to induce measles virus specific or $F$ or gp350 specific immune responses was examined in this more permissive animal model. Since sF3 demonstrated better immunogenicity than $\mathrm{sF} 1$ in cotton rats, only sF3 was evaluated in measles virus seropositive $(\mathrm{MV}+)$ rhesus macaques that had prior measles vaccination and measles virus seronegative (MV-) rhesus macaques. No abnormal clinical signs were observed and serum chemistries were within the normal range in all monkeys throughout the study (data not shown). $\mathrm{sF} 3$ or gp350 vaccinated monkeys induced a similar level of MV neutralizing antibody in both MV- and MV+ monkeys. A second dose of vaccination with $\mathrm{sF} 3$ or gp350 increased MV neutralizing $\mathrm{Ab}$ titers by about 4 -fold in all groups (Table 2 ). $\mathrm{The} \mathrm{Ab}$ titer differences between the groups were not statistically significant.

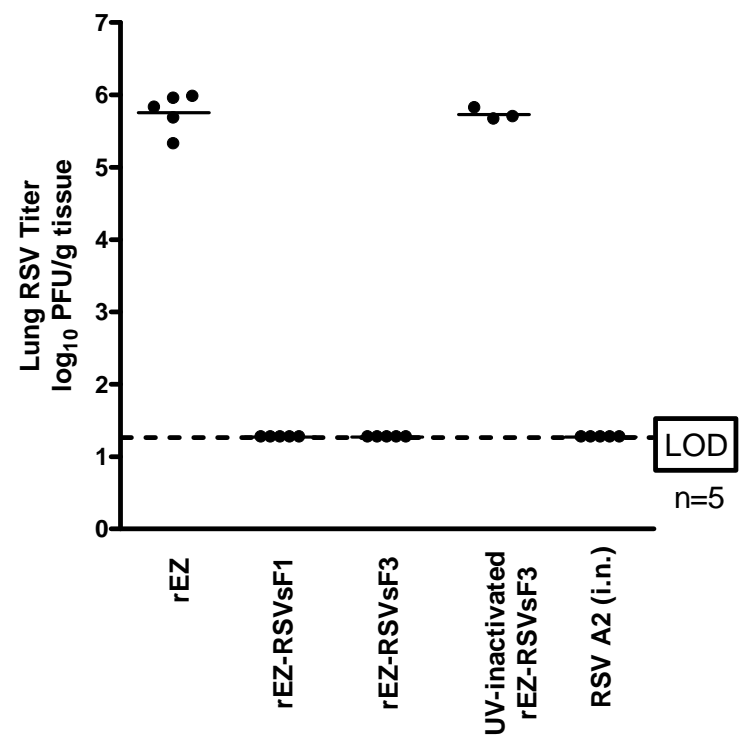

Fig. (4). Reduction of titers of RSV in the lungs of cotton rats vaccinated with measles-vectored RSV $F$ after challenge. Naïve cotton rats were immunized with $10^{5} \mathrm{PFU}$ of $\mathrm{sF} 1$ or $\mathrm{sF} 3$ on day 0 and 28. Cotton rats were then challenged with $10^{6} \mathrm{PFU}$ of RSV A2 on day 56. Lungs were harvested on day 60 and RSV titers were determined in the lung homogenates by standard plaque assay. Each experimental group represents 5 individual animals except in UVinactivated $\mathrm{sF} 3$ group $(\mathrm{n}=3)$.
Antibody responses to the inserted genes, however, were relatively low. sF3 inoculated animals had RSV F-specific IgG titer higher than the pre-vaccination level (titers were under the detection limit). F specific $\operatorname{IgG} \mathrm{Ab}$ titers were $9.3 \log _{2}$ and 8.8 $\log _{2}$ in MV+ and MV- groups after dose 1, respectively. After a second dose, three out of 4 animals in $\mathrm{MV}+$ group had more than 4-fold increase in RSV F-specific IgG Ab titer but none of the animals in MV- group had 4-fold increase in Ab response (Fig. 5A). After two doses of vaccination, RSV neutralizing Ab titers in all groups were very low in both MV+ and MV- groups. Seven out of 8 animals had a detectable level of RSV neutralizing $\mathrm{Ab}$. The RSV Nt Ab titers were not statistically different between the two groups $\left(5.0 \log _{2}\right.$ for MV+ versus 4.5 $\log _{2}$ for MV- groups) (Table 2). Ab responses to EBV gp350 in the gp350 vaccinated monkeys were not detected at all time points. Similar to antibody responses, IFN- $\gamma$ secreting cells in PBMC to measles viral antigens were significantly higher $(\sim 10-$ fold) than the responses to either RSV F or EBV gp350 (Fig. 5B) while $\mathrm{PBMC}$, when stimulated with measles viral antigens, RSV F or EBV gp350, did not secrete any IL-4. Thus, compared to the cotton rat studies, rEZ vectored viruses were poorly immunogenic in the primate model.

\section{DISCUSSION}

Reverse genetics has been developed for generating recombinant measles virus vectored vaccines encoding foreign antigens based on the Edmonston-Schwarz and AIK$\mathrm{C}$ vaccine strain $[15,48]$. The reverse genetic system described in this study was based on the EZ vaccine strain, which is used predominantly outside the US. The EZ strain might be immunogenic in population that has prior measles vaccine immunization [23]. The ectodomains of the RSV F and EBV gp350 glycoproteins instead of full length proteins were engineered to be expressed by EZ to avoid the incorporation of the foreign surface glycoproteins onto the measles virus envelope. The expression of heterologous membrane proteins on measles virus surface may alter the binding of measles to its natural receptors and thus change the tissue tropism of measles virus. We showed that both RSV F and EBV gp350 was expressed efficiently in vitro. However, rEZ vectored vaccines induced insert specific responses in cotton rats but poor responses in rhesus macaques although both cotton rats and rhesus macaques have previously been shown to be permissive to measles virus infection to various degrees [47, 49-51].

Table 2. Antibody Response of Rhesus Macaques to rEZ Vectored gp350 or F

\begin{tabular}{|c|c|c|c|c|c|c|c|c|}
\hline \multirow[t]{2}{*}{ Inoculation } & \multirow{2}{*}{$\begin{array}{c}\text { Prior MV } \\
\text { Vaccination }\end{array}$} & \multicolumn{3}{|c|}{$\begin{array}{l}\text { MV Neutralizing Ab } \\
\text { (mean } \log _{2} \pm \text { SD Titer) }\end{array}$} & \multicolumn{2}{|c|}{$\begin{array}{l}\text { RSV or EBV ELISA Ab } \\
\text { (Mean } \log _{2} \pm \text { SD Titer) }\end{array}$} & \multicolumn{2}{|c|}{$\begin{array}{l}\text { RSV or EBV Neutralizing Ab } \\
\quad\left(\text { Mean } \log _{2} \pm \text { SD Titer) }\right)^{\mathrm{c}}\end{array}$} \\
\hline & & Day 0 & Dose $1^{b}$ & Dose $2^{b}$ & Dose 1 & Dose 2 & Dose 1 & Dose 2 \\
\hline gp350 & + & $4.3 \pm 1.2$ & $5.7 \pm 0.5$ & $7.3 \pm 0.6$ & $<3.3$ & $<3.3$ & $<3.3$ & $<3.3$ \\
\hline gp350 & - & $<3.3$ & $5.4 \pm 1.1$ & $7.3 \pm 0.1$ & $<3.3$ & $<3.3$ & $<3.3$ & $<3.3$ \\
\hline sF3 & + & $4.2 \pm 0.7$ & $5.2 \pm 1.5$ & $7.5 \pm 1.2$ & $9.3 \pm 1.9$ & $11.8 \pm 1.0$ & $3.3 \pm 0.5$ & $5.0 \pm 0.8$ \\
\hline $\mathrm{sF} 3$ & - & $<3.3$ & $5.9 \pm 1.1$ & $7.9 \pm 1.1$ & $8.8 \pm 1.8$ & $9.5 \pm 2.1$ & $3.3 \pm 0.5$ & $4.5 \pm 1.7$ \\
\hline
\end{tabular}

${ }^{a}$ Previously vaccinated with Measles vaccine.

${ }^{\mathrm{b}}$ Serum samples were measured 4 weeks post dose 1 and 2 weeks post dose 2 .

${ }^{{ }^{c} \mathrm{RSV}}$ antibody titer is defined as $\log 2$ reciprocal dilution of serum that reduced plaques on HEp-2 cells by $50 \%$; neutralization assay was performed with $10 \%$ guinea pig complement.

Titers of prevaccinated animals were under the limit of detection in all the assays. 
A

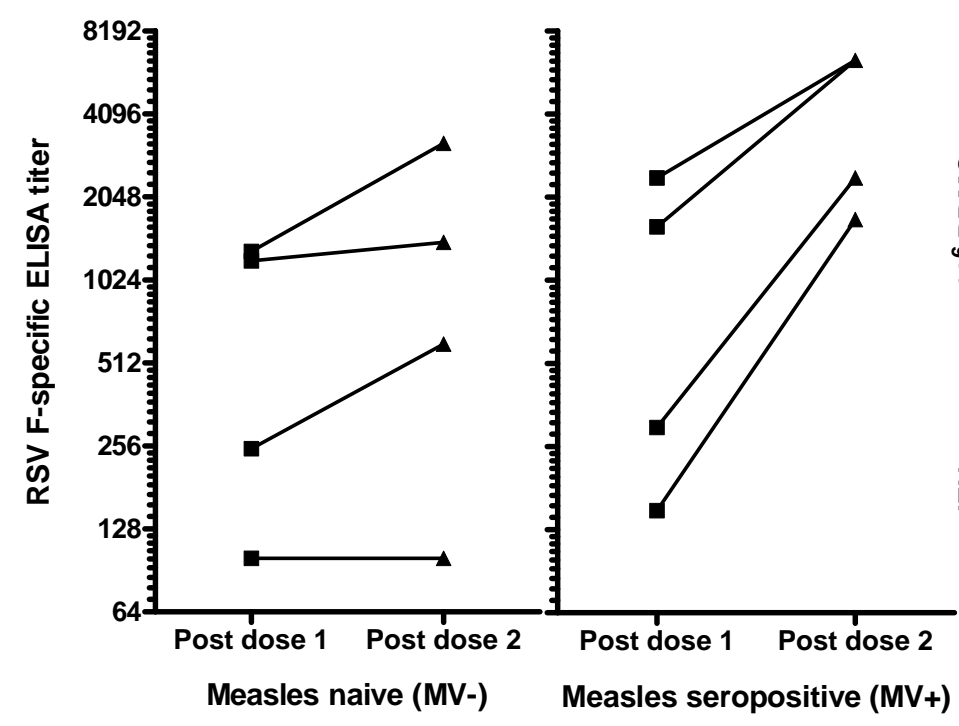

B

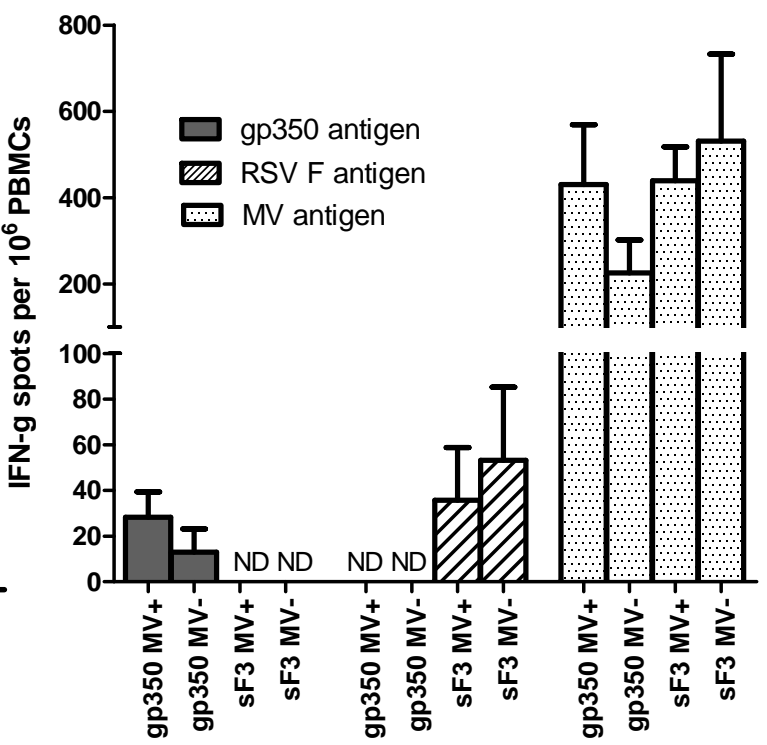

Fig. (5). RSV F specific antibody response and cellular response in rhesus macques vaccinated with measles vectors. Measles seronegative and sero-positive rhesus macaques were immunized with $10^{5} \mathrm{PFU}$ of sF3 or gp350 on day 0 and 28 . (A) RSV F titers were measured on day 28 (post dose 1) and 42 (post dose 2) using ELISA. (B) PBMCs were isolated from whole blood on day 56. The numbers of IFN- $\gamma$ spot forming cells were quantified with an ELISpot assay when PBMCs were stimulated with measles viral antigens, RSV F or EBV gp350 antigens in vitro. Spots were counted with an automated counting device and are expressed as numbers of spots per $10^{6}$ cells \pm SEM. $\mathrm{ND}=$ not determined

One of the important determinants for inducing a robust immune response in vivo is the amount of the expressed antigen level and antigen presentation. We have evaluated the effect of the gene insertion location and antigen expression level because transcription of nonsegmented negative strand RNA viruses is obligatorily sequential [52]. The genes located at proximal to the 3 ' promoter are produced more abundantly than the ones distal to the promoter [53]. Indeed, when RSV $F$ was introduced 3' proximally to the $\mathrm{N}$ gene, it produced 10 times more secreted RSV $F$ protein than when inserted between the $P$ and $M$ junction (data not shown). In comparison, insertion of the gp350 of EBV at the 1st position of EZ significantly affected virus replication. Insertion of the EBV gp350 gene between the $\mathrm{P}$ and $\mathrm{M}$ genes had less effect on virus growth, similar to that shown for Hepatitis B surface antigen (HBsAg) (14). The gene insertion position affected immunogenicity of EZ vectored vaccines in cotton rats. rEZ encoding RSV F ectodomain induced antibody response against measles and RSV F. rEZ-sF3 induced MV specific antibody response comparable to $\mathrm{rEZ}$ and $\mathrm{RSV}$ specific $\mathrm{Ab}$ response comparable to those induced by intranasal RSV infection in cotton rats; it also induced cell mediated response as measured by IFN- $\gamma$ ELISpot assay. Surprisingly, sF1 was inferior to $\mathrm{sF} 3$ in its ability to induce both RSV neutralizing antibody and RSV F-specific IFN- $\gamma$ secreting $\mathrm{T}$ cell responses, suggesting that $\mathrm{sF} 1$ may be more attenuated than $\mathrm{sF} 3$ in vivo. Immune response is dependent on viral infectivity and the nature of the inserts. rEZ vectored EBV gp350 and gp350tr induced lower gp350 specific IgG Ab response and undetectable neutralizing antibody response in cotton rats.

The cotton rats immunized with MV expressing RSV F were also challenged with wt RSV. After challenge, the number of IFN- $\gamma$ secreting cells was higher than IL-4 secreting cells, which was consistent with a Th1-biased response (data not shown). RSV enhanced disease has been associated with FI-RSV vaccine $[54,55]$. A chimeric parainfluenza virus vectored RSV F [35] did not cause enhanced disease in hamsters and has been proven to be safe in phase I clinical trial in seronegative children [56]. Recently, a report from another group has shown that measles virus vectored RSV F did not cause unusual pathology in cotton rats after RSV challenge, thus, the likelihood of the MV vector F to cause enhanced disease is very low [15].

Since cotton rats are partially permissive to $\mathrm{MV}, \mathrm{MV}$ vectored vaccine was further evaluated in rhesus macaques. Rhesus macaque is fully permissive to measles virus infection and the infected monkeys develop symptoms similar to those experienced by humans, such as skin rash, fever and conjunctivitis [47]. This monkey model was used in the neurovirulence testing of $\mathrm{MV}$ vaccine [57]. In addition, since rhesus macaques could be infected with human measles virus, the breeding colony is commonly vaccinated with MV. This allowed us to examine the effect of prior vaccination on vectored measles and mimic our target populations that either have maternal antibodies or have measles vaccination history. rEZ and rEZ expressing gp350 and sF3 induced a good level of antibody response to 
measles virus irrespective of their sero-status to MV. The antibody response was slightly lower in magnitude than what were observed in the cotton rats as the dose per $\mathrm{kg}$ used in the rhesus was $\sim 90$ times lower than in cotton rats. The antibody response to the $\mathrm{F}$ and gp350 inserts was much lower in rhesus macaques. A previous report showed that two doses of MV-HIV gp140 at $5 \times 10^{6}$ TCID $_{50}(25$ times higher dose than our study) induced a robust $\mathrm{Ab}$ response towards HIV gp140 in monkeys [10]. However, three doses of $10^{4} \mathrm{TCID}_{50}(1 / 15$ our dose) of MV vectored HBV surface antigen induced a very low response in monkeys [14]. Thus, the low humoral responses to the vectored inserts in rhesus macaques may be due to a lower dose used in this study.

Measles vaccine virus has been shown to bind signaling lymphocyte activation molecule (SLAM; also known as CD150) on activated immune cells and CD46 [58], which is ubiquitously expressed on human cells. It is thought that virus infects the respiratory tract through SLAM on dendritic cells. In cotton rats, although human CD46 and CD150 homologs have not been reported [59], measles virus could replicate in the lungs of these animals after intranasal infection [40]. We have evaluated different routes of administration (both intranasal and intramuscular) of MV vectored RSV F in cotton rats and found that both inoculation routes offered protection against RSV challenge after immunization (data not shown). Rhesus macaques possess both CD46 and CD150 receptor homologs [60] and are susceptible to measles virus infection and develop diseases similar to humans. The difference in receptors between the two animal species may be able to explain why insertion of the insert into EZ strain have further attenuated viruses and reduced immunogenicity of the virus in rhesus macaques but not in cotton rats.

We also examined replication of EZ vectored RSV F and EBV gp350 in vivo by using real time qRT-PCR since differential in growth kinetics of recombinant measles virus may explain the difference in antibody responses. However, we were not able to detect measles genomes in PBMC isolated from whole blood 24 hours post vaccination. This may be attributed to the low copies of measles virus circulating in the blood or the time point used to measure measles kinetics in vivo was not optimal. In conjunction, we have examined replication of EZ vectors in PBMC of rhesus macaques ex vivo to determine if insertion of the foreign gene affected replication of these viruses in PBMC. PHAactivated PBMC cells were infected with $\mathrm{rMV}$ at MOI of 1.0 and growth kinetics were determined for 7 days. The peak titer of the recombinant viruses containing RSV F or EBV gp350 were only $0.5 \log _{10}$ lower than rEZ (data not shown), indicating the vectored vaccine could infect rhesus cells. We also investigated genetic stability of the insert by serially passaging the recombinant viruses in Vero cells 10 times and did not find the loss of the inserted gene expression as reported previously [61, 62].

Other negative stranded RNA viruses including Newcastle disease virus (NDV), vesicular stomatitis virus, Sendai virus and parainfluenza viruses [35, 63-65] had been evaluated as vectors to deliver foreign antigens and were shown to elicit both humoral and cellular responses in nonhuman primates and to confer protection to virus challenge in some cases $[63,66-69]$. The vectored vaccines were normally delivered to non-human primates by either intranasal or intratracheal inoculation route. We found intranasal and intramuscular vaccination of EZ induced similar antibody response in cotton rats. It is possible that intranasal immunization might be more immunogenic than intramuscular vaccination in monkeys.

Based on our study, MV vector is probably not suitable for delivery of the EBV gp350 antigen. Immunogenicity of adjuvanted gp350 protein vaccine has been demonstrated in young adults [29], adjvanted gp350 might be the right approach for EBV vaccine development. The amount of gp350 delivered by MV is likely not sufficient to induce gp350 specific immune response. The $\mathrm{F}$ protein of RSV delivered by MV is more immunogenic than EBV gp350, however, additional evaluation of immunogenicity of MVRSV F must be conduced before proceeding to testing this vaccine in humans.

\section{ACKNOWLEDGEMENTS}

We thank Rosemary Broom for obtaining EZ vaccine strain, MedImmune's Animal Care Facility for conducting the cotton rat studies, Jeff Roberts and Phil Allen at Valley Biosystems for conducting the monkey study, Jennifer Woo, Jason Marshall, Stacie Lambert, Darren Heeke, Lorrie Gemmell for conducting $T$ cells assays, Chin-Fen Yang for sequencing support, Dr. Gary van Nest for reviewing the manuscript.

\section{CONFLICT OF INTEREST}

None declared.

\section{REFERENCES}

[1] Liniger M, Zuniga A, Naim HY. Use of viral vectors for the development of vaccines. Expert Rev Vaccines 2007; 6(2): 255-66.

[2] Amanna IJ, Carlson NE, Slifka MK. Duration of humoral immunity to common viral and vaccine antigens. N Engl J Med 2007; 357(19): 1903-15.

[3] Gans HA, Yasukawa LL, Alderson A, et al. T cell immunity to measles viral proteins in infants and adults after measles immunization. Viral Immunol 2004; 17(2): 298-307.

[4] Ovsyannikova IG, Dhiman N, Jacobson RM, Vierkant RA, Poland GA. Frequency of measles virus-specific CD4+ and CD8+ T cells in subjects seronegative or highly seropositive for measles vaccine. Clin Diagn Lab Immunol 2003; 10(3): 411-6.

[5] Hiremath GS, Omer SB. A meta-analysis of studies comparing the respiratory route with the subcutaneous route of measles vaccine administration. Hum Vaccin 2005; 1(1): 30-6.

[6] Low N, Kraemer S, Schneider M, Restrepo AM. Immunogenicity and safety of aerosolized measles vaccine: systematic review and meta-analysis. Vaccine 2008; 26(3): 383-98.

[7] Cantarella G, Liniger M, Zuniga A, et al. Recombinant measles virus-HPV vaccine candidates for prevention of cervical carcinoma. Vaccine 2009; 27(25-26): 3385-90.

[8] del Valle JR, Devaux P, Hodge G, Wegner NJ, McChesney MB, Cattaneo R. A vectored measles virus induces hepatitis B surface antigen antibodies while protecting macaques against measles virus challenge. J Virol 2007; 81(19): 10597-605.

[9] Liniger M, Zuniga A, Tamin A, et al. Induction of neutralising antibodies and cellular immune responses against SARS coronavirus by recombinant measles viruses. Vaccine 2008; 26(17): 2164-74.

[10] Lorin C, Mollet L, Delebecque F, et al. A single injection of recombinant measles virus vaccines expressing human immunodeficiency virus (HIV) type 1 clade $B$ envelope glycoproteins induces neutralizing antibodies and cellular immune responses to HIV. J Virol 2004; 78(1): 146-57.

[11] Despres P, Combredet C, Frenkiel MP, Lorin C, Brahic M, Tangy F. Live measles vaccine expressing the secreted form of the West 
Nile virus envelope glycoprotein protects against West Nile virus encephalitis. J Infect Dis 2005; 191(2): 207-14.

[12] Iankov ID, Haralambieva IH, Galanis E. Immunogenicity of attenuated measles virus engineered to express Helicobacter pylori neutrophil-activating protein. Vaccine ; 29(8): 1710-20.

[13] Lorin C, Delebecque F, Labrousse V, et al. A recombinant live attenuated measles vaccine vector primes effective HLA-A0201restricted cytotoxic $\mathrm{T}$ lymphocytes and broadly neutralizing antibodies against HIV-1 conserved epitopes. Vaccine 2005; 23(36): 4463-72.

[14] Reyes-del Valle J, Hodge G, McChesney MB, Cattaneo R. Protective anti-hepatitis B virus responses in rhesus monkeys primed with a vectored measles virus and boosted with a single dose of hepatitis B surface antigen. J Virol 2009; 83(17): 9013-7.

[15] Sawada A, Komase K, Nakayama T. AIK-C measles vaccine expressing fusion protein of respiratory syncytial virus induces protective antibodies in cotton rats. Vaccine 2010;29(7): 1481-90.

[16] Zuniga A, Wang Z, Liniger M, et al. Attenuated measles virus as a vaccine vector. Vaccine 2007; 25(16): 2974-83.

[17] Wang Z, Hangartner L, Cornu TI, et al. Recombinant measles viruses expressing heterologous antigens of mumps and simian immunodeficiency viruses. Vaccine 2001; 19(17-19): 2329-36.

[18] Brandler S, Lucas-Hourani M, Moris A, et al. Pediatric measles vaccine expressing a dengue antigen induces durable serotypespecific neutralizing antibodies to dengue virus. PLoS Negl Trop Dis 2007; 1(3): e96.

[19] Rager-Zisman B, Bazarsky E, Skibin A, et al. The effect of measles-mumps-rubella (MMR) immunization on the immune responses of previously immunized primary school children. Vaccine 2003; 21(19-20): 2580-8.

[20] Sepulveda-Amor J, Valdespino-Gomez JL, Garcia-Garcia Mde L, et al. A randomized trial demonstrating successful boosting responses following simultaneous aerosols of measles and rubella (MR) vaccines in school age children. Vaccine 2002; 20(21-22): 2790-5.

[21] Wong-Chew RM, Beeler JA, Audet S, Santos JI. Cellular and humoral immune responses to measles in immune adults reimmunized with measles vaccine. J Med Virol 2003; 70(2): 276-80.

[22] Albrecht P, Ennis FA, Saltzman EJ, Krugman S. Persistence of maternal antibody in infants beyond 12 months: mechanism of measles vaccine failure. J Pediatr 1977; 91(5): 715-8.

[23] Tidjani O, Grunitsky B, Guerin N, et al. Serological effects of Edmonston-Zagreb, Schwarz, and AIK-C measles vaccine strains given at ages 4-5 or 8-10 months. Lancet 1989; 2(8676): 1357-60.

[24] McIntosh K, Chanock RM. Respiratory syncytial virus. Second Edition ed. New York: Raven Press, Ltd., 1990.

[25] Olmsted RA, Elango N, Prince GA, et al. Expression of the F glycoprotein of respiratory syncytial virus by a recombinant vaccinia virus: comparison of the individual contributions of the $F$ and G glycoproteins to host immunity. Proc Natl Acad Sci U S A 1986; 83(19): 7462-6.

[26] Connors M, Collins PL, Firestone CY, Murphy BR. Respiratory syncytial virus (RSV) F, G, M2 (22K), and N proteins each induce resistance to RSV challenge, but resistance induced by M2 and N proteins is relatively short-lived. J Virol 1991; 65(3): 1634-7.

[27] Fleisher G, Henle W, Henle G, Lennette ET, Biggar RJ. Primary infection with Epstein-Barr virus in infants in the United States: clinical and serologic observations. J Infect Dis 1979; 139(5): 5538.

[28] Lopes V, Young LS, Murray PG. Epstein-Barr virus-associated cancers: aetiology and treatment. Herpes 2003; 10(3): 78-82.

[29] Sokal EM, Hoppenbrouwers K, Vandermeulen C, et al. Recombinant gp350 vaccine for infectious mononucleosis: a phase 2, randomized, double-blind, placebo-controlled trial to evaluate the safety, immunogenicity, and efficacy of an Epstein-Barr virus vaccine in healthy young adults. J Infect Dis 2007 196(12): 174953 .

[30] Schneider H, Spielhofer P, Kaelin K, et al. Rescue of measles virus using a replication-deficient vaccinia-T7 vector. J Virol Methods 1997; 64(1): 57-64.

[31] Radecke F, Spielhofer P, Schneider H, et al. Rescue of measles viruses from cloned DNA. EMBO J 1995; 14(23): 5773-84.

[32] Mann GF, Allison LM, Copeland JA, Agostini CF, Zuckerman AJ. A simplified plaque assay system for measles virus. J Biol Stand 1980; 8(3): 219-25.
[33] Jackman WT, Mann KA, Hoffmann HJ, Spaete RR. Expression of Epstein-Barr virus gp350 as a single chain glycoprotein for an EBV subunit vaccine. Vaccine 1999; 17(7-8): 660-8.

[34] Christe KL, McChesney MB, Spinner A, et al. Comparative efficacy of a canine distemper-measles and a standard measles vaccine for immunization of rhesus macaques (Macaca mulatta). Comp Med 2002; 52(5): 467-72.

[35] Tang RS, Schickli JH, MacPhail M, et al. Effects of human metapneumovirus and respiratory syncytial virus antigen insertion in two 3' proximal genome positions of bovine/human parainfluenza virus type 3 on virus replication and immunogenicity. J Virol 2003; 77(20): 10819-28.

[36] Sashihara J, Burbelo PD, Savoldo B, Pierson TC, Cohen JI. Human antibody titers to Epstein-Barr Virus (EBV) gp350 correlate with neutralization of infectivity better than antibody titers to EBV gp42 using a rapid flow cytometry-based EBV neutralization assay. Virology 2009; 391(2): 249-56.

[37] Mok H, Lee S, Utley TJ, et al. Venezuelan equine encephalitis virus replicon particles encoding respiratory syncytial virus surface glycoproteins induce protective mucosal responses in mice and cotton rats. J Virol 2007; 81(24): 13710-22.

[38] Zhan X, Slobod KS, Krishnamurthy S, et al. Sendai virus recombinant vaccine expressing hPIV-3 $\mathrm{HN}$ or $\mathrm{F}$ elicits protective immunity and combines with a second recombinant to prevent hPIV-1, hPIV-3 and RSV infections. Vaccine 2008; 26(27-28): 3480-8.

[39] Tanner J, Whang Y, Sample J, Sears A, Kieff E. Soluble gp350/220 and deletion mutant glycoproteins block Epstein-Barr virus adsorption to lymphocytes. J Virol 1988; 62(12): 4452-64.

[40] Wyde PR, Ambrose MW, Voss TG, Meyer HL, Gilbert BE. Measles virus replication in lungs of hispid cotton rats after intranasal inoculation. Proc Soc Exp Biol Med 1992; 201(1): 80-7.

[41] Jin H, Zhou H, Cheng X, Tang R, Munoz M, Nguyen N. Recombinant respiratory syncytial viruses with deletions in the NS1, NS2, SH, and M2-2 genes are attenuated in vitro and in vivo. Virology 2000; 273(1): 210-8.

[42] Murphy BR, Sotnikov AV, Lawrence LA, Banks SM, Prince GA. Enhanced pulmonary histopathology is observed in cotton rats immunized with formalin-inactivated respiratory syncytial virus (RSV) or purified F glycoprotein and challenged with RSV 3-6 months after immunization. Vaccine 1990; 8(5): 497-502.

[43] Wu H, Pfarr DS, Johnson S, et al. Development of motavizumab, an ultra-potent antibody for the prevention of respiratory syncytial virus infection in the upper and lower respiratory tract. J Mol Biol 2007; 368(3): 652-65.

[44] Munoz JL, McCarthy CA, Clark ME, Hall CB. Respiratory syncytial virus infection in C57BL/6 mice: clearance of virus from the lungs with virus-specific cytotoxic T cells. J Virol 1991; 65(8): 4494-7.

[45] de Vries $\mathrm{RD}$, Lemon $\mathrm{K}$, Ludlow $\mathrm{M}$, et al. In vivo tropism of attenuated and pathogenic measles virus expressing green fluorescent protein in macaques. J Virol; 84(9): 4714-24.

[46] McChesney MB, Miller CJ, Rota PA, et al. Experimental measles. I. Pathogenesis in the normal and the immunized host. Virology 1997; 233(1): 74-84

[47] Zhu YD, Heath J, Collins J, et al. Experimental measles. II. Infection and immunity in the rhesus macaque. Virology 1997; 233(1): 85-92.

[48] Combredet C, Labrousse V, Mollet L, et al. A molecularly cloned Schwarz strain of measles virus vaccine induces strong immune responses in macaques and transgenic mice. J Virol 2003; 77(21): 11546-54.

[49] Niewiesk S, Prince G. Diversifying animal models: the use of hispid cotton rats (Sigmodon hispidus) in infectious diseases. Lab Anim 2002; 36(4): 357-72.

[50] de Swart RL, Ludlow M, de Witte L, et al. Predominant infection of CD150+ lymphocytes and dendritic cells during measles virus infection of macaques. PLoS Pathog 2007; 3(11): e178.

[51] El Mubarak HS, Yuksel S, van Amerongen G, et al. Infection of cynomolgus macaques (Macaca fascicularis) and rhesus macaques (Macaca mulatta) with different wild-type measles viruses. J Gen Virol 2007; 88(Pt 7): 2028-34.

[52] Abraham G, Banerjee AK. Sequential transcription of the genes of vesicular stomatitis virus. Proc Natl Acad Sci U S A 1976; 73(5): 1504-8. 
[53] Ray J, Fujinami RS. Characterization of in vitro transcription and transcriptional products of measles virus. J Virol 1987 Nov;61(11):3381-7.

[54] Kapikian AZ, Mitchell RH, Chanock RM, Shvedoff RA, Stewart CE. An epidemiologic study of altered clinical reactivity to respiratory syncytial (RS) virus infection in children previously vaccinated with an inactivated RS virus vaccine. Am J Epidemiol 1969; 89(4): 405-21

[55] Kim HW, Canchola JG, Brandt CD, et al. Respiratory syncytial virus disease in infants despite prior administration of antigenic inactivated vaccine. Am J Epidemiol 1969; 89(4): 422-34.

[56] Bernstein DI, Malkin E, Abughali N, Falloon J, Yi T, Dubovsky F. Phase 1 Study of the Safety and Immunogenicity of a Live, Attenuated Respiratory Syncytial Virus and Parainfluenza Virus Type 3 Vaccine in Seronegative Children. Pediatr Infect Dis J 2011 Sep 15.

[57] Sharova OK, Rozina EE, Shteinberg LS, Gordienko NM, Kolyanova IS. Morphological characterisitcs of the pathological process in the central nervous system of monkeys infected with variants of measles virus strain L-16. Acta Virol 1979; 23(5): 3937.

[58] Dorig RE, Marcil A, Chopra A, Richardson CD. The human CD46 molecule is a receptor for measles virus (Edmonston strain). Cell 1993; 75(2): 295-305.

[59] Pfeuffer J, Puschel K, Meulen V, Schneider-Schaulies J, Niewiesk S. Extent of measles virus spread and immune suppression differentiates between wild-type and vaccine strains in the cotton rat model (Sigmodon hispidus). J Virol 2003; 77(1): 150-8.

[60] Dorig RE, Marcil A, Richardson CD. CD46, a primate-specific receptor for measles virus. Trends Microbiol 1994; 2(9): 312-8.
[61] Binder JJ, Hoffman MA, Palmenberg AC. Genetic stability of attenuated mengovirus vectors with duplicate primary cleavage sequences. Virology 2003; 312(2): 481-94.

[62] Mueller S, Wimmer E. Expression of foreign proteins by poliovirus polyprotein fusion: analysis of genetic stability reveals rapid deletions and formation of cardioviruslike open reading frames. J Virol 1998; 72(1): 20-31.

[63] Bukreyev A, Huang Z, Yang L, et al. Recombinant newcastle disease virus expressing a foreign viral antigen is attenuated and highly immunogenic in primates. J Virol 2005; 79(21): 13275-84.

[64] Hurwitz JL, Soike KF, Sangster MY, et al. Intranasal Sendai virus vaccine protects African green monkeys from infection with human parainfluenza virus-type one. Vaccine 1997; 15(5): 533-40.

[65] Perez M, Clemente R, Robison CS, et al. Generation and characterization of a recombinant vesicular stomatitis virus expressing the glycoprotein of Borna disease virus. J Virol 2007; 81(11): 5527-36.

[66] Kato M, Igarashi H, Takeda A, et al. Induction of Gag-specific Tcell responses by therapeutic immunization with a Gag-expressing Sendai virus vector in macaques chronically infected with simianhuman immunodeficiency virus. Vaccine 2005; 23(24): 3166-73.

[67] Matano T, Kobayashi M, Igarashi $\mathrm{H}$, et al. Cytotoxic $\mathrm{T}$ lymphocyte-based control of simian immunodeficiency virus replication in a preclinical AIDS vaccine trial. J Exp Med 2004; 199(12): 1709-18.

[68] Rose NF, Marx PA, Luckay A, et al. An effective AIDS vaccine based on live attenuated vesicular stomatitis virus recombinants. Cell 2001; 106(5): 539-49.

[69] Tang RS, MacPhail M, Schickli JH, et al. Parainfluenza virus type 3 expressing the native or soluble fusion (F) Protein of Respiratory Syncytial Virus (RSV) confers protection from RSV infection in African green monkeys. J Virol 2004; 78(20): 11198-207.

(C) Mok et al.; Licensee Bentham Open.

This is an open access article licensed under the terms of the Creative Commons Attribution Non-Commercial License (http: //creativecommons.org/licenses/by-nc/ 3.0/) which permits unrestricted, non-commercial use, distribution and reproduction in any medium, provided the work is properly cited. 